Interactive comment on "The effects of ice and hillslope erosion and detrital transport on the form of detrital thermochronological age probability distributions from glacial settings" by Maxime Bernard et al.

\author{
Todd A. Ehlers (Referee) \\ todd.ehlers@uni-tuebingen.de \\ Received and published: 16 March 2020
}

SUMMARY:

This is a very interesting study that advances our knowledge of how glacial (and to a lesser degree hill slope) processes can be evaluated using detrital thermochronometer samples from end moraines. The authors present results from a well-developed 2 nd order glacier flow and erosion model. The model is roughly tuned to simulate the Waddington Region (Tiedemann Glacier), British Columbia where a large data set of 
bedrock, ice cored moraine detritus, and glacial outwash detritus, apatite (U-Th)/He and apatite fission track ages have been published (i.e. data from Ehlers et al. 2015; Enkelmann and Ehlers, 2015). I collected the samples the authors use in this study and am very familiar with the study area (and data). The authors use particle tracking in the model to determine what the age-distribution of eroded material will be in the end moraine. The primary results of the study focus on the time scale required to reach an equilibrium age distribution in the frontal moraine, and also spatial variations in upstream catchment erosion.

The content of this manuscript is highly relevant for this journal, and the results are new and significantly advance our knowledge of this topic. The topic addressed is important because it covers the exciting field of linking detrital thermochronology to geomorphic processes. Overall, I am very supportive of eventual publication of this manuscript. However, in it's current form, there are many aspects of the study that are difficult to understand, and some additional analysis and potentially a few model sensitivity simulations are required before it should be considered for publication. I've provided below detailed comments on areas of the manuscript where I struggled to understand the results and interpretations. In many cases, my suggestions may not be correct -but they are based on my understanding of the text and nevertheless highlight portions of the manuscript that need additional clarification for all readers. The authors should feel free to contact me if any of the comments are not clear.

Based on the above, and following, comments, I recommend major revisions and rereview.

\section{GENERAL COMMENTS:}

G1. The general validity (beyond the simulations presented) of the authors results and interpretations is difficult to assess. If I understand the text and Table 1 correctly, the authors present a set of simulations with with only one set of parameters. These results are nicely presented and described, but the primary interpretations of the paper (e.g.

ESurfD

Interactive comment
Printer-friendly version

Discussion paper

\section{(}


1,500 yr equilibrium time for observed age-distributions; sediment trapping in tributary glaciers, hill slope vs. Glacial contributions to observed age-distributions) are based on this single (?) set of chosen parameters. The results would be generalisable and more broadly applicable if a small set of additional simulations with a sensitivity analysis were included. For example, picking the least well constrained climate, ice, and hill slope parameters and picking reasonable values above and below what is shown in Table 1 should be considered to evaluate how robust the interpretations are in the text. I suggest these additional figures be shown in the supplementary material and then referred to in the main text, or highlighted in a new discussion section with a new figure that compare results.

G2. The results of Enkelmann and Ehlers (2015, Chem Geo) compared AFT ages across the ice cored moraine, outwash, and older moraines in front of the modern glacial terminus. The ice cored moraine and outwash samples were statistical identical (Fig. 6E), meaning that multiple ice cored samples when combined produce the same grain-age distribution as outwash. "slight differences" were observed between the individual ice cored moraine material in this study (Fig. 4 of Enkelmann and Ehlers). While the authors of this study (Bernard et al) explicitly say they are not trying to match observations in their study, in the discussion section they end making statements that do compare / evaluate the observations. There are suggested revisions related to this:

G2-a. In the start of the paper when describing the previous observational studies in the area (and the bedrock data you use), please add text that makes it clearer how these data were collected and which data sets are or are not relevant to how the model is setup and why. For example, the Enkelmann and Ehlers 2015 data are well suited for comparison to the model results (they come from ice cored moraine material at the end of the glacier). In contrast - the Ehlers et al. 2015 data are from glacial outwash and are not suitable for comparison to how the model is setup. The modeling approach does not track particles through the subglacial hydrologic system. No comparisons to this later study should be made in this manuscript.

\section{ESurfD}

Interactive comment
Printer-friendly version

Discussion paper 
G2-b. The concluding discussion section (4.4) and Fig. 10 make model predictions that are more or less comparable to the observations of Enkelmann and Ehlers, 2015. Although some qualitative comparisons are made in the text, the manuscript would be much stronger if the data from Enkelmann and Ehlers, 2015 were also plotted in Fig. 10c and similarities / discrepancies are discussed.

G3. The model setup and description needs to be clearer. It is not clear how erosion is done for hill slopes and how ages from hill slopes are mixed with the glacial sourced ages. It would greatly improve a readers understanding of this study if the coupling (and particle tracking) between hill slopes and glaciers was better explained, and also the sensitivity of their results (e.g. Fig. 7) to some of these parameters (e.g. see also comment G1 above). I also don't understand exactly how the 'uniform' erosion model was calculated with the ice model (see detailed comment below). The methods sections needs to explain the model setup for all this better. Section 2.1 (end) explains a non-linear diffusion model is used for hill slopes, but it's not described in enough detail how the sediment transport is done in this part of the landscape. The paper later on nicely explores how hill slope vs. Glacial sediment sources impact detrital cooling ages. Thus, some additional text in the methods section would make it much easier to understand the model results. As it's written now, I could not reproduce your results if I wanted to.

G4. Comparison of distributions should include statistical tests. Section 4.4 (see also detailed comment 26 below) presents an analysis of how representative point samples across a moraine compare to the mean of all samples and the bedrock distribution. This section is very useful for understanding how and where people could sample. However, the analysis does not statistically evaluate if the different synthetically sampled distributions are the same or not. Visual / qualitative comparisons of distributions is dangerous, and I suspect (based on experience) that several of the distributions show in Fig. 10c will be statistically identical. If this section remains in the paper (which I hope it does), it's important the authors conduct a simple KS or Kuiper test

\section{ESurfD}

Interactive

comment
Printer-friendly version

Discussion paper 
to see if in fact the different distributions show in figure 10c are different or not. This comment could also potentially impact the conclusions presented in section 4.5. The text in section 4.4 and 4.5 is good, but simply needs support from a more quantitative comparison. Finally, as mentioned above for comment G2, this model result should be compared to observations that were collected from roughly this same area (Enkelmann and Ehlers, 2015).

G5. The text is in general well written and clear. However, there are many small wording issues / grammatical problems throughout the text (e.g. missing articles, subject/verb agreement) that are understandably hard to catch for a non-native speaker. I recommend a native speaker/co-author give the text another thorough read to correct these.

\section{SPECIFIC COMMENTS:}

0 . For clarity - all axis labels with 'Age' on them should say what age (e.g. "AFT Age") you are plotting since you work with two different systems in this study.

1. Abstract should make it clear if the langragian particle tracking is only for ice flow, or subglacial water.

2. Page 2 paragraph starting at line 17: Also relevant to the content of this paragraph, and the study area investigated is the study by Yanites and Ehlers 2016 that documents how glacial sliding relates to bedrock thermochronometer ages (in a neighbouring valley in the Coast Mountains). Yanites, B. J. and Ehlers, T. A.: Intermittent glacial sliding velocities explain variations in long-timescale denudation, Earth and Planetary Science Letters, 450, 52-61, doi:10.1016/j.epsl.2016.06.022, 2016.

Also - this manuscript is highly relevant to the following previous work and the authors should consider citing it in the introduction or discussion. Herman, F.,et al., 2018. The response time of glacial erosion. JGR - Earth Surface. https://doi.org/10.1002/2017JF004586

Interactive comment 
3. Page (pg) 3, line (In) 12 - It might be worth clarifying here for readers that the Enkelmann and Ehlers 2015 studied sampled ICE across the ablation zone, and the Ehlers et al. 2015 study sampled glacial OUTWASH. This would help readers understand why you can not directly compare model predictions to one of these sets of observations..

4. Pg5, 6 model description. Hydrology effects on sliding are described here, but please also add a sentence or two that says if this is also included in the particle tracking for making SPDFs of cooling ages. Maybe you address this later.

5. Pg5, 6 - It is also important that this section says how you have calibrated the model for the subsurface hydrology. This aspect of the model is likely very important for how the data are interpreted, so some text on this aspect would be useful.

6. Pg.6 - Your approach assumes all sediment comes from quarrying. I'm more or less ok with this (note fine sediment fractions were present in what we sampled for this glacier). However, please explain here if you account for the comminution (breaking down) of plucked material. Why could this be important? If $20 \times 20 \mathrm{~cm}$ rock is plucked in the upper reaches of the catchment it will break down during transport and provide fine grain material that was sampled. If a $20 \times 20 \mathrm{~cm}$ rock is plucked from $100 \mathrm{~m}$ from the sample point - it wouldn't show up in sample. The material sampled for the Tiedemann glacier ice cored moraine and outwash was a 'bulk' sediment sample, but with nothing greater than $\sim 2 \times 2 \mathrm{~cm}$ size in it. I would be great if your modeling approach accounted for comminution, but l'm guessing this is not the case. So this effect needs to be acknowledged and the potential implications of it discussed in a model caveats section.

7. Pg 6/7 - section 2.3. As indicated above, please explicitly state that water transport of detritus is not accounted for. Fluvial systems mix sediment very efficiently and the flow rates on these outlet rivers are high (rounded cobbles were in the river bed and appeared transported by it).

8. Pg. 8 section 2.3. Please add some text saying how the glacial mass balance (and climate inputs) are calculated and refer to your table.

ESurfD

Interactive comment
Printer-friendly version

Discussion paper 
9. Fig. 4c, d - I suggest labelling the x-axis with the age plotted (e.g. "AHe Age" for c). Also - for the caption, mention what uncertainty you used for making the PDFs since this influences the smoothness of the curves relative to panel B. Caption should also explicitly say the data come from glacial outwash, not moraine.

10. Pg12 In7. Please say under what conditions the equilibrium state was calculated, and how closely it matches the present day thickness and length of the glacier.

11. Fig. 5. Please provide a more descriptive caption of what model this is at the start of the caption. Also - what are you actually doing with the 'hillslope' vs. 'glacial' parts of the catchment (Fig. 5a). It's not clear from the text (or caption) if you are also feeding hill slope material into the SPDFs calculated.

12. Pg13, In1-2. Reword sentence please.

13. Fig. 6 - caption needs a starting sentence saying in general what is plotted and what model it comes from. Also- again for panel c, $d$ - indicate the age type ("AHe Age") on the x-axis. Please do this for all other figures if this is also the case. It makes it much easier to read the figures quickly.

14. Pg.14 In1. Please explain better what you mean by "model with uniform erosion". I'm confused because I don't understand how you made the ice model have uniform erosion - and where the uniform erosion was applied (e.g. Hillslopes and glacial areas?). Fig. 7e kinda gets at this, but the text should explain it better. Thanks.

15. Pg. 16 top. After reading this page (related to previous comment) I'm still confused - and some clarification is needed on this paragraph and what was actually calculated. The start of the paragraph needs to explain better what the objective of this comparison is (hillslope vs. glaciers). Also In3-4 are confusing because I thought this section only about uniform erosion, but this sentence says you are comparing a detrital SPDF to the uniform erosion model. Are you talking about the OBSERVED detrital SPDF? Perhaps make it clear throughout the text by always using 'observed' vs. 'modeled' detrital

\section{ESurfD}

Interactive comment
Printer-friendly version

Discussion paper 
16. Pg16, In10+. This paragraph is also unclear. After reading all of section 3.3 - I'm confused as a reader. Please rewrite this section to make it clearer of a) what is the logic behind the experiment / comparison conducted, b) what is the first and second order main trends in the results and what data / model results results (bedrock vs. Detrital you're looking at, and c) summary sentence(s) with the key observation to take away.

17. Maybe I missed it earlier, but after reading the results section - I think the methods section needs to be expanded some to explain how you look at (or calculate) hillsope vs. Glacial contributions to the detrital cooing ages.

18. Pg16 In 29. I don't understand how "we computed a new. ..." How did you compute this? Assuming uniform erosion? Using a diffusion based hill slope transport law? Please elaborate.

19. Pg.17 In5-10. This result is entirely dependent on the assume hill slope transport law used, and diffusivity,....right? Perhaps mention this, and also make it clearer (per my previous comments) how the curve in Fig. 7 is calculated.

20. Pg. $18 \ln 1$. Several times in the paper you refer to or tune the model to an erosion rate $1 \mathrm{~mm} / \mathrm{yr}$. Why did you use this value? This should be explained in the methods section.

21. Pg.18 In1-4. I don't understand this sentence and where these numbers you cite are coming from. For example, where is $31 \mathrm{~mm} / \mathrm{yr}$ coming from? Where are the uncertainties in the numbers later in the sentence coming from?

22. Pg. 18. Ln6. Please rewrite this sentence. I don't understand it.

23. Pg. $19 \ln 1$. "traducing"? Not sure what you're trying to say.

23. Pg $19 \ln 20$. Please expand this thought (particle tracking is in ice, not sub-glacial

\section{ESurfD}

Interactive comment 
drainage). I would describe in general (qualitative) terms how the results could differ if subglacial outwash was sampled (e.g. how Ehlers et al. 2015 sampled). F

ESurfD

24. Pg. 19. Ln 24-25 "spatial erosion pattern can be biased on the detrital SPDF (e.g. Ehlers et al. 2015)". Please remove the "e.g. Ehlers et al. 2015". You may be correct that there is a bias, but you haven't shown this because the Ehlers et al. samples were from OUTWASH, not from ice. Also - your timescale arguments for bias later in the paragraph would likely be severely decreased if outwash is sampled because transit times of water to the outlet are significantly faster than for ice. So, please either show that Ehlers et al. 2015 have a bias in their outwash sample interpretation, or remove the reference to this paper to be fair. Final note concerning the general conclusions you are trying to make here about timescales - while your description is accurate for the simulations you present, it's hard to know if this is really a general result with any sensitivity tests to your model parameters presented in the study. Please consider adding sensitivity tests in the supplemental material and referring to them in the text.

Table 1 - please be more specific about what you mean by "variable" in some rows. I think what you mean is that these variables are 'internally calculated'

25. Pg. $21 \ln 29-30$. This isn't really a surprise is it that moraines will more closely represent glacial erosion than hill slopes? Also - doesn't this statement and paragraph sort of contradict the previous section where you say there would be a bias towards low elevations in SPDFs? Maybe I'm missing something here - but perhaps more text (in the previous section about biases) relating to what section 4.3 is saying would help clarify things more.

26. Pg.22 section 4.4. This is nice that you done this analysis. However, to do this type of comparison you need to test if the distributions show in Fig. 10c are in fact statistically different. To do this, you need to apply a KS (or Kuiper) test of the distributions. Please include this type of analysis to see if these distributions really are in fact different at the $95 \%$ confidence level. This comment also potentially impacts the

Interactive comment

Printer-friendly version

Discussion paper 
interpretations presented in section 4.5.

27. Pg. 24 In 1-2. This conclusion is correct for the simulations presented, but how variable is this result if there are variations in some of the model parameters. A sensitivity test of model inputs would help readers see if this result is general, or specific to your model simulations.

28. Pg. $24 \ln 22-23$ "However, we also emphasis ..." This statement should be removed or significantly expanded \& justified. How many grains should be sampled is a significant topic on it's own, and this study doesn't address this. The typical "100" grains minimum that people site from Vermeesch is not actually correct for these types of detrital samples (we have a paper in preparation that goes through the statistics of number of detrital AHe samples needed for different catchment sizes and it's complicated).

29. Supplementary materials. There is useful material presented in the supplement, but the figure captions are a too sparse for some figures. Please expand the figure captions some to be more descriptive of what is shown. For example, what model simulation is shown in the figure, and perhaps also what section of the text the figure is relevant to.

Overall a nice piece of work. I enjoyed reading this study.

*** End of Review ***

Interactive comment on Earth Surf. Dynam. Discuss., https://doi.org/10.5194/esurf-2020-7, 2020.

\section{ESurfD}

Interactive comment 